\title{
Lack of reliability of self-reports by patients with advanced colorectal polyps
}

\author{
Benjamin Fiedler ${ }^{1}$, Lawrence Fiedler ${ }^{2}$, Michael A. DeDonno² ${ }^{2}$ Kosi Anago ${ }^{2}$, Leonie de la Cruz ${ }^{2}$, George R. Luck², \\ Charles H. Hennekens ${ }^{2}$ \\ ${ }^{1}$ Cornell University College of Arts and Sciences, Ithaca, $N Y ;{ }^{2}$ Charles E. Schmidt College of Medicine, Florida Atlantic University, Boca Raton, \\ FL, USA
}

Virtually all guidelines concerning screening for colorectal cancer in the United States recommend that health care providers rely on self-reports of personal history of colorectal polyps and cancer in their patients as well as their first-degree relatives. ${ }^{1}$ Specifically, health care providers are required to rely on self-reports by their patients to perform risk stratification. All such guidelines assume that patients have an accurate knowledge of their personal history, and have communicated the information to their first-degree relatives.

Our primary goal was to address the reliability of self-reports by quantitating patient knowledge and communication to first-degree relatives concerning removal of their advanced colorectal polyp. The availability a single large pathology laboratory accredited by the College of American Pathologists that services 55 endoscopy practices afforded a unique opportunity to collect information concerning the knowledge of the patient of their biopsy proven advanced colorectal polyp as well as their communication to first-degree relatives.

The protocol was approved by the Institutional Review Board of Florida Atlantic University (IRB Net ID 734261-1). During

Received October 22, 2018. Revised October 31, 2018.

Accepted November 5, 2018.

Correspondence to Lawrence Fiedler, Charles E. Schmidt College of

Medicine, Florida Atlantic University, 2300 Glades Road, Suite 201E, Boca

Raton, FL 33431, USA. Tel: +1-561-317-3433, Fax: +1-561-393-1729,

E-mail: larfied@yahoo.com

ORCID Benjamin Fiedler (https://orcid.org/0000-0002-6198-5515), Lawrence Fiedler (https://orcid.org/0000-0003-1297-8316), Charles H. Hennekens (https://orcid.org/0000-0003-1214-1663) the period between July 1, 2013 and June 30, 2017, there were 249 consecutive patients aged 40 to 91 years who had colonoscopies that led to a diagnosis of biopsy proven advanced colorectal polyps. After obtaining informed consent, we were able to secure complete interview data from a case series of 84 willing and eligible patients (33.7\%). The self-reports by patients about their knowledge of their biopsy proven diagnosis as well as their communication to first-degree relatives were obtained from brief telephone interviews that consisted of eleven questions from semi-structured questionnaires. The interviews were conducted by 1 of 2 female medical assistants certified by American Medical Technologies. The questionnaires contained information on first, the knowledge of patient concerning his or her biopsy proven diagnosis of advanced colorectal polyps, second, the communication of their biopsy proven diagnosis to their first-degree relatives.

For each variable, the data were coded and frequencies of the self-reports of their biopsy proven diagnosis of advanced colorectal polyps as well as their communication to their firstdegree relatives were calculated.

Of the 84 patients, 39 (46.4\%) were men, 45 were women, and their mean age was 66 with a range from 41 to 91 years. Among the 84 patients with biopsy proven advanced colorectal polyps, 10 (11.9\%) were unaware that they had undergone removal of a polyp. In addition, 46 patients (54.8\%) did not inform their first-degree relatives. Finally, 69 (82.1\%) were unaware of the type of polyp removed and, therefore, could not know that they had been diagnosed with advanced colorectal 
polyps.

In this case series of 84 patients with biopsy proven colorectal polyps, $11.9 \%$ were unaware that any polyp had been removed, $82.1 \%$ were unaware of the advanced nature of their polyps, and $54.8 \%$ failed to inform their first-degree relatives. These data indicate a lack of reliability of self-reports by patients with biopsy proven advanced colorectal polyps. These data contrast with the reliability of self-reports and communication to first-degree relatives of colorectal cancer. ${ }^{2}$ Perhaps not surprisingly, these findings suggest that patients are far less likely to recall the diagnosis of benign, albeit advanced, colorectal polyps than a diagnosis of colorectal cancer. Thus, it seems rational for clinicians to be able to rely on self-reports and communication to family members of colorectal cancer but not benign, albeit advanced, polyps.

Several limitations to this study merit consideration. First is the low response rate which may, at least in theory, have led to a biased result. ${ }^{3}$ Although we cannot accurately estimate either the magnitude or direction of any bias, we believe that the respondents in this case series are more likely to represent a more knowledgeable subgroup than the general U.S. population. Specifically, this study population is homogeneous with regard to having health insurance as well as residing in 4 relatively affluent counties in South Florida (Broward, Dade, Martin, and Palm Beach). In addition, health care literacy tends to correlate with socioeconomic status. ${ }^{4}$ We believe that such socioeconomic factors are unlikely to affect the validity but may influence the generalizability of the findings as the lack of reliability of self-reports is likely to be even greater among the uninsured and less affluent. As a consequence, these results are likely to underestimate the lack of reliability of both personal knowledge of the patient of their biopsy proven diagnosis of advanced colorectal polyps as well as their accurate communication to first-degree relatives.

Despite these and other potential limitations, we believe the most plausible interpretation of the data to be that they contribute to the formulation of the hypothesis that clinicians may not be able to rely on self-reports of biopsy proven advanced colorectal polyps as well as their communication to first-degree relatives. Busy clinicians are faced with the challenging task of obtaining accurate data regarding personal and family history to decide upon the most appropriate strategies to screen and detect colorectal cancer in their patients. To do so, clinicians may wish to consider gathering reliable histologic data on personal and family history of colorectal polyps. These efforts should include younger patients in whom the incidence of colorectal cancer is increasing. ${ }^{5}$ The increases in colorectal cancer may be due, at least in part, to the epidemics of overweight and obesity ${ }^{6,7}$ as well as type 2 diabetes mellitus. ${ }^{8}$ Primary prevention efforts are paramount and major challenges to busy clinicians. Another major challenge in screening is to obtain more reliable information from patients about their personal history of colorectal polyps and achieving better communication to their first-degree relatives. Overcoming these clinical challenges will enhance prevention and screening efforts but must include the acquisition of reliable data about colorectal polyps as well as the communication to first-degree relatives. These multifactorial approaches should achieve the most good for the most patients concerning prevention as well as screening and early diagnosis and treatment of colorectal cancer.

\section{FINANCIAL SUPPORT}

The authors received no financial support for the research, authorship, and/or publication of this article.

\section{CONFLICT OF INTEREST}

B.F., L.F., M.A.D., K.A., L.D. and G.R.L. report no disclosures. C.H.H. discloses that he serves as an independent scientist in an advisory role to investigators and sponsors as Chair or Member of Data and Safety Monitoring Boards for Amgen, British Heart Foundation, Cadila, Canadian Institutes of Health Research, DalCor, Lilly, Regeneron and the Wellcome Foundation; to the U.S. Food and Drug Administration and UpToDate; receives royalties for authorship or editorship of 3 textbooks and as coinventor on patents for inflammatory markers and cardiovascular disease that are held by Brigham and Women's Hospital; has an investment management relationship with the West-Bacon Group within SunTrust Investment Services, which has discretionary investment authority and does not own any common or preferred stock in any pharmaceutical or medical device company.

\section{AUTHOR CONTRIBUTION}

Study concept and design, data acquisition, interpretation, drafting and revising manuscript: Fiedler B. Data acquisition, administrative, technical and material support, interpretation, revising manuscript: Fiedler L. Data analysis and interpretation, revising manuscript: DeDonno MA. Revising question- 
naire, obtaining IRB approval, revising manuscript: Anago K, de la Cruz L, Luck GR. Study design, questionnaire development, interpretation, revising manuscript: Hennekens CH. Approval of final manuscript: all authors.

\section{ACKNOWLEDGEMENTS}

The authors are indebted to Aja Samuels, RMA and Tammy Leonard, RMA, for their expert assistance in conducting the interviews on potentially eligible patients with biopsy proven advanced colorectal polyps kindly provided by Digestive Care.

\section{REFERENCES}

1. Rex DK, Boland CR, Dominitz JA, et al. Colorectal cancer screening: recommendations for physicians and patients from the U.S. Multi-Society Task Force on colorectal cancer. Am J Gastroenterol 2017;112:1016-1030.

2. Aitken J, Bain C, Ward M, Siskind V, MacLennan R. How accurate is self-reported family history of colorectal cancer? Am J
Epidemiol 1995;141:863-871.

3. Hennekens CH, Buring JE. Epidemiology in medicine. Boston: Little, Brown and Co, 1987.

4. Hosking SM, Brennan-Olsen SL, Beauchamp A, Buchbinder R, Williams LJ, Pasco JA. Health literacy in a population-based sample of Australian women: a cross-sectional profile of the Geelong Osteoporosis Study. BMC Public Health 2018;18:876.

5. Singh KE, Taylor TH, Pan CG, Stamos MJ, Zell JA. Colorectal cancer incidence among young adults in California. J Adolesc Young Adult Oncol 2014;3:176-184.

6. Garvey WT, Garber AJ, Mechanick JI, et al. American Association of Clinical Endocrinologists and American College of Endocrinology consensus conference on obesity: building an evidence base for comprehensive action. Endocr Pract 2014; 20:956-976.

7. Sherling DH, Perumareddi P, Hennekens CH. Metabolic syndrome. J Cardiovasc Pharmacol Ther 2017;22:365-367.

8. Hennekens CH, Pfeffer MA, Newcomer JW, Jellinger PS, Garber A. Treatment of diabetes mellitus: the urgent need for multifactorial interventions. Am J Manag Care 2014;20:357-359. 